\title{
Técnicas Agrícolas: Territorialidades e Saberes
}

\author{
Técnicas Agrícolas: Territorialidad y Saberes \\ Agricultural Techniques: Territorialities and Knowledge
}

\author{
Kety da Costa Maciel $^{1}$ \\ Silvana Maria Gritti²
}

\begin{abstract}
Resumo
O presente trabalho visa apresentar um recorte do Projeto de Intervenção que está sendo desenvolvido junto ao Curso de Mestrado Profissional em Educação da Universidade Federal do Pampa sob o título: "As Técnicas Agrícolas na formação dos alunos do Campo" e que tem por tema o ensino e aprendizagem das Técnicas Agrícolas no contexto do campo. Seu desdobramento inicial trata de entender como a territorialidade onde a escola se insere reflete no currículo da escola, na visão dos estudantes. O objetivo da pesquisa é compreender como os saberes, conhecimentos e os fatores que determinaram a constituição do assentamento tem influenciado na formação do currículo do componente curricular denominado Técnicas Agrícolas. A metodologia adotada é qualitativa por meio da pesquisa-ação e sua primeira etapa foi a realização da pesquisa exploratória para constituição do diagnóstico orientador da ação. Para realizar esta investigação utilizou-se a aplicação de uma atividade de produção de relato no Google Drive, recurso tecnológico desenvolvido pela empresa/plataforma Google. Os resultados obtidos no diagnóstico apontam para a ausência da escola na relação com a produção da vida do campo. Fica perceptível a necessidade de uma educação que contemple as especificidades alicerçadas no Princípio Pedagógico da Educação no Movimento Sem-Terra "A realidade como base de produção do conhecimento". Portanto, aponta-se a compreensão da especificidade desses vínculos entre território, terra, lugar e escola como um dos componentes da especificidade da formação de educadoras e educadores do campo.
\end{abstract}

Palavras-Chave: Técnicas Agrícolas; Territorialidade; Saberes do campo.

\section{Resumen}

Este artículo tiene como objetivo presentar un recorte del Proyecto de Intervención que se está desarrollando a lo largo del Máster Profesional en Educación de la Universidad Federal de Pampa bajo el título: "Las técnicas agrícolas en la formación de los estudiantes de campo" y que tiene como tema la enseñanza y aprendizaje de técnicas agrícolas en el contexto del campo. Su desarrollo inicial es comprender cómo la territorialidad donde se inserta la escuela se refleja en el currículum escolar, desde la perspectiva de los estudiantes. El objetivo de la investigación es comprender cómo el conocimiento, el conocimiento y los factores que determinaron la constitución del asentamiento han influido en la formación del componente curricular llamado Técnicas Agrícolas. La metodología adoptada es cualitativa a través de la investigación en acción y su primer paso fue la realización de investigaciones exploratorias para constituir el diagnóstico guía de la acción. Para llevar a cabo esta investigación, utilizamos la aplicación de una actividad de informes en Google Drive, un recurso tecnológico desarrollado por la empresa / plataforma Google. Los resultados obtenidos en el diagnóstico apuntan a la ausencia de escuela en relación con la producción de la vida rural. Es evidente la necesidad de una educación que aborde las especificidades basadas en el Principio pedagógico de la educación en el movimiento sin tierra "La realidad como base de la producción de conocimiento". Por lo tanto, se señala la comprensión de la especificidad de estos vínculos entre territorio, tierra, lugar y escuela como uno de los componentes de la especificidad de la educación de los educadores del campo.

Palabras claves: Tecnicas agricolas; Territorialidad; Saberes del campo.

\footnotetext{
1 Mestranda em Educação; Universidade Federal do Pampa; Herval, Rio Grande do Sul, Brasil; ketycosta73@gmail.com

2 Doutora em Educação; Universidade Federal do Pampa; Jaguarão, Rio Grande do Sul, Brasil; silvanagritti@gmail.com
} 


\begin{abstract}
This paper aims to present a clipping of the Intervention Project that is being developed along the Professional Master's Degree in Education of the Federal University of Pampa under the title: "The Agricultural Techniques in the formation of the field students" and which has as its theme the teaching and learning of Agricultural Techniques in the context of the field. Its initial development is to understand how the territoriality where the school is inserted reflects in the school curriculum, in the students' view. The objective of the research is to understand how the knowledge, knowledge and factors that determined the constitution of the settlement have influenced the formation of the curriculum component called Agricultural Techniques. The methodology adopted is qualitative through action research and its first step was the conduction of exploratory research to constitute the guiding diagnosis of action. To carry out this investigation we used the application of a reporting activity in Google Drive, a technological resource developed by the company / platform Google. The results obtained in the diagnosis point to the absence of school in relation to the production of rural life. It is noticeable the need for an education that addresses the specificities based on the Pedagogical Principle of Education in the Landless Movement "Reality as the basis of knowledge production". Therefore, it is pointed the understanding of the specificity of these bonds between territory, land, place and school as one of the components of the specificity of the education of educators of the field.
\end{abstract}

Keywords: Agricultural techniques; Territorialidad; Knowledge of the field.

\title{
1. Introdução
}

Atualmente os estudos sobre educação do campo cresceram muito, impulsionados principalmente pelos movimentos sociais. A escola do campo foi pensada a partir do contexto urbano, mantendo o distanciamento da realidade do contexto do campo, negando o campo como espaço de educação, de evolução social e de formação de identidades.

Para isso, a educação do Movimento dos Trabalhadores Rurais Sem Terra (MST) reafirma a luta de classes que deve estar presente nas escolas, assim como instiga o entendimento de como a territorialidade onde a escola se insere reflete no currículo da escola. Neste sentido, a pesquisa aqui empreendida pode ser um divisor de águas, quando busca compreender como os saberes, conhecimentos e fatores que determinaram a constituição do Assentamento têm influenciado na formação do currículo do componente curricular denominado Técnicas Agrícolas, sendo esse o objetivo do estudo. Portanto, esse artigo é um recorte do Projeto de intervenção do curso de Mestrado Profissional em Educação da Universidade Federal do Pampa (UNIPAMPA) intitulado “As Técnicas Agrícolas na formação do aluno do campo".

O território pode ser considerado o espaço de identidade ou de identificação, pode ser vivido ou sonhado e a partir desse pertencimento, desse imaginário ou até mesmo desse sonho que sua construção tem início. Entende-se que movidos pela sobrevivência, pela necessidade de enraizamento e por acreditarem no valor social da terra junto ao sentimento de viver em cooperação com o próximo é que o povo camponês luta pela conquista de um espaço no campo para poder viver com dignidade humana e em harmonia com os recursos naturais. 
A Educação do campo é pensada por estudiosos que acreditam no valor social da terra e nos saberes e fazeres do povo campesino. Entre eles podemos destacar Roseli Caldart (2004) e Miguel Arroyo (1999) que discutem a Educação do Campo em seus aspectos legais, culturais e territoriais e oferecem suporte para esta pesquisa.

Este estudo trata-se de uma discussão teórica, situada no âmbito do projeto de intervenção do Mestrado Profissional em Educação e discute a Proposta Curricular da Escola e o propósito da disciplina Técnicas Agrícola como elemento viabilizador da discussão sobre saberes e territorialidade. Essa pesquisa em nível de mestrado, conta com a realização de uma pesquisa-ação, amparada por uma pesquisa exploratória, por meio de uma atividade de produção de relato no Google Drive, recurso tecnológico desenvolvido pela empresa/plataforma Google. Os resultados obtidos no diagnóstico apontam para a escola na relação com a produção da vida do campo. Aqui, entretanto, analisamos a proposta pedagógica, situando-a dentro de um contexto mais amplo, relacionando como princípios da Educação do MST e algumas resoluções nacionais que amparam a Educação do Campo.

\section{Relação da Escola com o Movimento dos Trabalhadores Rurais Sem Terra}

Os sujeitos pesquisados pertencem a Escola Neuza Brizola, que está localizada no campo e é uma das conquistas do povo camponês. Entretanto, essa escola não se configura como um espaço para memória de sua história. Digo isso por não ter uma proposta que trate aspectos relevantes envolvendo o surgimento da escola, os objetivos que motivaram o povo do Assentamento a reunirem-se em assembleia para discutir o acesso à educação para seus filhos, a luta diária e persistente por partes de professores, dos alunos e pais, que se doaram em prol da continuidade e aperfeiçoamento do espaço educacional conquistado, entre outros importantes fatores.

Não existem propostas na escola para datas festivas que envolvam temáticas relacionadas ao dia do colono, rodas de conversas das famílias assentadas com a comunidade escolar para recontar a história da escola no contexto camponês em que se encontra, mostra de produtos da agricultura familiar cultivados no Assentamento, entre outras ações que envolvam o contexto. A proposta educacional ou até mesmo a prática de cada docente é influenciada por características urbanas, possivelmente capitalistas. A Escola mostra distanciamento dos princípios educacionais pensadas pelo Movimento dos Trabalhadores Rurais.

Conforme os Princípios da Educação no Movimento dos Trabalhadores Sem Terra, publicados no Caderno de Educação número 8, do ano de 1996, são 13 os princípios filosóficos e pedagógicos. O primeiro é: "Educação para a transformação social. Educação de 
classe, massiva, organicamente vinculada ao movimento social, aberta ao mundo para a ação e aberta para o novo" (MOVIMENTO DOS TRABALHADORES RURAIS SEM TERRA, 1996, p. 10). Analisando a práxis que se realiza na escola, posso afirmar que este princípio, embora orientador, se coloca como um ideal, pois a escola em seu Projeto PolíticoPedagógico (PPP) contempla que:

A Escola Municipal de Ensino Fundamental Neuza Brizola assume como missão, a formação da pessoa em seus aspectos intelectual, físico, social, moral e afetivo, pelo desenvolvimento da sensibilidade, da capacidade de reflexão, de pensamento autônomo e de ação, de modo a levá-la a assumir um posicionamento diante da vida, autodeterminar-se conscientemente e a contribuir dignamente para a construção de um mundo melhor (PEDRAS ALTAS, 2013, p. 15).

Na sequência a filosofia da escola traz que:

A filosofia da Escola Municipal de Ensino Fundamental Neuza Brizola é o compromisso com a formação ética, política e social dos educandos, respeitando seus saberes e o meio em que vivem para a transformação social. E assim, contribuir para a definição de sua identidade de escola do campo e para a construção de um mundo mais justo, mais humano e democrático onde as pessoas possam viver inspiradas pelos valores de liberdade, solidariedade e respeito mútuo (PEDRAS ALTAS, 2013, p. 15).

A vinculação da escola com o movimento é ocasional, apresenta-se em algumas ações discentes, assim como no PPP. Nesse sentido pode-se dizer que as práticas educativas da escola não trazem elementos claros que afirmem uma educação de classe na perspectiva dos trabalhadores Assentados.

O princípio filosófico dois "Educação para o trabalho e a cooperação" (MOVIMENTO DOS TRABALHADORES RURAIS SEM TERRA, 1996, p. 10) é um princípio importante nesta pesquisa, pois o componente curricular Técnicas Agrícolas se coloca como a disciplina com potencial de articular dimensões importantes do trabalho do campo. A análise da proposta da disciplina nos leva a compreender que tanto o conceito de trabalho, como o de cooperação, que a fundamentam reproduzem a concepção hegemônica de trabalho e cooperação sob o capitalismo.

O princípio pedagógico "A realidade como base de produção do conhecimento" (MOVIMENTO DOS TRABALHADORES RURAIS SEM TERRA, 1996, p. 10) realiza-se no cotidiano da Escola Neuza Brizola quando o campo é visto como espaço de produção de conhecimento e a proposta educacional parte do contexto.

Ainda nos princípios pedagógicos estão:

1) Relação entre teoria e prática.

2) Combinação metodológica entre processo de ensino e de capacitação [...].

4) Conteúdos formativos socialmente úteis.

5) Educação para o trabalho e pelo trabalho.

6) Vínculo orgânico entre processos educativos e processos políticos.

7) Vínculo orgânico entre processos educativos e processos econômicos. 
8) Vínculo orgânico entre educação e cultura.

9) Gestão democrática.

10) Auto-organização dos/das estudantes.

11)Criação de coletivos pedagógicos e formação permanente dos educadores/das educadoras.

12) Atitude e habilidades de pesquisa.

13)Combinação entre processos pedagógicos coletivos e individuais (MOVIMENTO DOS TRABALHADORES RURAIS SEM TERRA, 1996, p. 24).

No sentindo da proposta por uma educação do campo com viés social, humano, em sistema de incentivo à colaboração, assim como o contexto como ponto de partida para a produção do conhecimento que tratam os princípios educacionais do MST, não são abordados de forma clara no texto do PPP, embora o documento citado ofereça autonomia na organização das atividades para os professores, que podem organizar suas aulas voltadas para o contexto. Ainda em relação aos documentos da Escola que direcionam a organização da mesma e a proposta de trabalho, é visto que as propostas que são direcionadas ao contexto do campo suprimem informações do ponto de vista que a escola é fruto da conquista do Movimento Sem Terra, sendo que deveria ter metas focadas nos princípios do Movimento.

A escola trabalha a ideia do homem do campo como sujeito que precisa ser domesticado para o viver em sociedade e aprimorar os conhecimentos para melhores resultados na produção, visto que para o sistema atual o homem do campo é o principal elemento capaz de elevar o acúmulo do capital, através de sua mão de obra, operando máquinas, trabalhando arduamente nas grandes lavouras com insumos que oferecem riscos à saúde. As práticas educacionais atuais ensinam como viver em sociedade para ser bem aceito pelo capitalismo, escravo do consumismo e com pensamento empreendedor, ou seja, como ser vassalo da hegemonia capitalista.

As práticas docentes devem ser esclarecedoras do valor do homem camponês como ser humano que produz qualidade de vida através do modo de relacionar-se com o meio ambiente. Para que essas ações educativas se tornem reais é relevante a participação dos docentes frente à proposta de currículo que será oferecida aos alunos do campo e em especial à disciplina de Técnicas Agrícolas, que contempla parte diversificada do contexto do campo. O campo é um espaço de possibilidades que incentiva a relação entre seres humanos. Para construir uma política de educação do campo referenciada para a grande diversidade é permanentemente desencadeada uma luta que envolve movimentos sociais, na afirmação do protagonismo dos sujeitos do campo na definição de seu projeto educativo calçado a partir da perspectiva da formação humana para o povo camponês. Para isso o Ministério da Educação (MEC) por meio do Conselho Nacional de Educação (CNE) e sua Câmara de Educação Básica (CEB) aprovou a Resolução $n^{\circ}$ 1, de 3 de abril de 2002 que instituiu diretrizes 
operacionais para a Educação Básica nas Escolas do Campo. De acordo com o artigo $3^{\circ}$ das Diretrizes:

O Poder Público, considerando a magnitude da importância da educação escolar para o exercício da cidadania plena e para o desenvolvimento de um país cujo paradigma tenha como referências a justiça social, a solidariedade e o diálogo entre todos, deverá garantir a universalização do acesso da população do campo à Educação Básica e à Educação Profissional de Nível Técnico (BRASIL, 2002).

Ainda nas Diretrizes Operacionais, no artigo $6^{\circ}$ (BRASIL, 2002):

As responsabilidades com atendimento escolar e à luz da diretriz legal do regime de colaboração entre a União, os Estados, o Distrito Federal e os Municípios, proporcionará Educação Infantil e Ensino Fundamental nas comunidades rurais, inclusive para aqueles que não o concluíram na idade prevista, cabendo em especial aos Estados garantir as condições necessárias para o acesso ao Ensino Médio e à Educação Profissional de Nível Técnico.

Passados seis anos o MEC, CNE e CEB aprovam a Resolução no 2, de 28 de abril de 2008 que no art. $1^{\text {o }}$ afirma:

A Educação do Campo compreende a Educação Básica em suas etapas de Educação Infantil, Ensino Fundamental, Ensino Médio e Educação Profissional Técnica de nível médio integrada com o Ensino Médio e destina-se ao atendimento às populações rurais em suas mais variadas formas de produção da vida-agricultores familiares, extrativistas, pescadores artesanais, ribeirinhos, assentados e acampados da Reforma Agrária, quilombolas, caiçaras, indígenas e outros (BRASIL, 2008).

As reformas educacionais na Educação do campo emergem dos movimentos sociais e têm sido implantadas em contraponto às concepções ideológicas de uma Educação Rural, marcada pela valorização do capitalismo. $\mathrm{O}$ acesso à escola pode ser considerado um avanço na legislação educacional, porém também precisam ser pensadas as condições para permanência do aluno do campo na escola do campo. No bojo das políticas educacionais identificamos duas concepções ideológicas de educação para as populações do campo, uma atrelada à educação rural, marcada pela valorização do agronegócio e, de outro lado, a Educação do Campo enquanto “[...] prática coletiva de construção de conhecimentos emancipatórios e no cenário de um projeto nacional transformador das relações de exclusão, exploração e desigualdades" (SOUZA; MARCOCCIA, 2011, p. 193).

O parágrafo $\S 1^{\circ}$, do artigo $1^{\circ}$ da resolução $n^{\circ} 2$ de 28 de abril de 2008 afirma que:

A Educação do Campo, de responsabilidade dos Entes Federados, que deverão estabelecer formas de colaboração em seu planejamento e execução, terá como objetivos a universalização do acesso, da permanência e do sucesso escolar com qualidade e todo o nível da Educação Básica (BRASIL, 2008).

Aqui é preciso pensar no que se refere à educação de qualidade e perceber qual é a educação que está sendo oferecida, que concepção de educação está presente nesta oferta.

Quando situamos a educação como um processo de transformação humana, de emancipação humana, percebemos quanto os valores do campo fazem parte da 
história da emancipação humana. Então como a escola vai trabalhá-los? Será que a escola vai ignorá-los? Será suficiente pegar o livro da cidade e apenas adaptá-lo? A questão é mais fundamental, é ir às raízes do campo e trabalhá-las, incorporá-las como uma herança coletiva que mobiliza e inspira lutas pela terra, pelos direitos, por um projeto democrático e que também pede educação (ARROYO, 1999, p. 24).

É um processo educativo em que a voz que pede mudança, precisa ser escutada, o suor dor rosto do povo campesino que luta dia a dia pela sobrevivência, deve ser notado, é momento para os saberes e o fazeres do campesinato serem considerados, para que novas ações educacionais sejam projetadas.

Ainda tratando dos parágrafos do art. $1^{\circ}$ da resolução $n^{\circ} 2$, de 28 de abril de 2008:

$\S 2^{\circ}$ A educação do campo será regulamentada e oferecida pelos Estados, pelo distrito Federal e pelos Municípios, nos respectivos âmbitos de atuação prioritária. $27 \S 3^{\circ}$ A Educação do Campo será desenvolvida, preferentemente, pelo ensino regular $\S 4^{\circ}$ A Educação do campo deverá atender, mediante procedimentos adequados, na modalidade da Educação de Jovens e Adultos, as populações rurais que não tiveram acesso ou não concluíram seus estudos, no Ensino Fundamental ou no Ensino Médio, em idade própria. Art $5^{\circ} \S 1^{\circ}$ Sempre que possível, o deslocamento dos alunos, como previsto no caput, deverá ser feito do campo para o campo, evitando-se ao máximo, o deslocamento do campo para a cidade (BRASIL, 2008).

No município de Pedras Altas a educação no campo é oferecida através Ensino Fundamental, não sendo oferecido na modalidade Educação de Jovens e Adultos (EJA), embora a comunidade demonstre interesse em concluir seus estudos ou até mesmo serem alfabetizados. Os alunos são transportados para a escola no Assentamento Nossa Senhora da Glória, por ser o local mais próximo e evitar gastos ao Poder Público, não por pensarem no aluno camponês que tem o direito de estudar próximo a sua casa e facilitar a locomoção para que esse aluno chegue motivado na escola, mas sim para diminuir custos. Os aspectos legais acima citados amparam o acesso do povo do campo à escola em seu contexto, mas não basta apenas o acesso, a educação precisa ser pensada, planejada e executada no campo e para o campo, tendo como ponto de partida a realidade camponesa. O povo camponês é um povo que luta por sobrevivência, por produção de vida com qualidade e equilíbrio com questões sociais como o cuidado com o meio ambiente, através de um aproveitamento do solo para produção de alimentos sem agrotóxicos, construindo assim a agricultura familiar. Nesse sentido, no próximo subtítulo resgata-se a história do componente curricular de Técnicas Agrícolas e a contribuição do mesmo na formação de alunos trabalhadores do campo na Escola Municipal de Ensino Fundamental Neuza Brizola.

\section{Técnicas Agrícolas: histórico e contribuição}

No ano de 1996, a Escola Municipal de Ensino Fundamental Neuza Brizola iniciou suas atividades educacionais. A Escola foi uma conquista da Comunidade do Assentamento 
Nossa Senhora da Glória, que em assembleia, elegeram os 28 representantes para contatar com o Secretário de Educação do município de Herval, com o intuito do mesmo autorizar o funcionamento da escola na comunidade e nessa época propuseram o empréstimo da casa da fazenda, desapropriada para funcionamento da escola. Nos primeiros meses a escola contava com cem alunos e apenas dois professores, que atendiam de forma multisseriada. Não foram encontrados registros dessa época, os acontecimentos são contados pela diretora da Escola, que na época era uma das professoras. A professora também relatou que por ser escola da zona rural, veio da Secretaria de Educação de Herval a proposta curricular e já constava a disciplina de Técnicas Agrícolas. A diretora ainda complementa que diversas vezes as atividades de Técnicas Agrícolas foram substituídas por jogos de futebol. Após a emancipação de Pedras Altas no ano de 2000, a Escola passou a pertencer ao novo município e a proposta curricular foi reelaborada pela Secretaria de Educação de Pedras Altas, no ano de 2013.

De acordo com a proposta curricular:

A disciplina de Técnicas agrícolas vem beneficiar as escolas em todos os níveis de ensino, melhorando as condições de acesso a educação de pequenos cultivos e criações de animais principalmente nas escolas de áreas rurais, diversificando produtos que assumem importante papel nas economias de mercado (PEDRAS ALTAS, 2013, p. 47).

O Objetivo geral da Disciplina de Técnicas Agrícolas de acordo com a proposta curricular é:

Fornecer elementos para a compreensão dos problemas específicos de produção agropecuária, introduzindo vocabulário técnico, as principais condicionantes ambientais e socioeconômicas da produção agrícola, as operações culturais e panorama da agricultura a nível nacional (PEDRAS ALTAS, 2013, p. 47).

Observa-se que a proposta da disciplina traz o modelo de modernização capitalista quando trata da agropecuária, do vocabulário técnico e das condições climáticas para essas ações, não referindo-se no objetivo principal em sustentabilidade, agricultura familiar e ecologia. Nesse sentido, não caracteriza as especificidades do contexto, o que determina o distanciamento das práticas discentes em relação ao contexto dos alunos. A descontextualização, para Caldart (2004) está atrelada ao encurtamento dos horizontes políticos e educacionais para os povos do campo, o qual reflete a visão pessimista do campo e da educação do campo pautada na crença de que para mexer na terra ou cuidar do gado não são necessários nem letras, nem competências. Não é necessário escola.

Os objetivos específicos da disciplina de Técnicas Agrícolas de acordo com a proposta curricular são: 
Proporcionar melhorias no desenvolvimento das escolas de área rural, estimular a prática de pequenas culturas e a criação de animais, reconhecer técnicas para dar continuidade a produção rural de suas famílias, incentivar cursos de graduação na formação de profissionais para atuarem na área rural (PEDRAS ALTAS, 2013, p. 49).

Para quem observa o processo de desenvolvimento da disciplina de Técnicas Agrícolas do ponto de vista dos setores populares, é possível perceber que o projeto do capitalismo está presente na proposta da referida disciplina, quando a mesma silencia princípios que norteiam a produção da agricultura familiar. Aqui, salienta-se que a escola pode e deve ser um espaço de debate para uma melhor qualidade de vida humana. O quadro a seguir apresenta uma síntese dos conteúdos e objetivos da Disciplina de Técnicas Agrícolas.

Quadro 1: Objetivos e conteúdos do componente curricular de Técnicas Agrícolas

\begin{tabular}{|l|l|}
\hline Agricultura & Conceitos, evolução, noção de sistema \\
\hline $\begin{array}{l}\text { Principais Técnicas de } \\
\text { produção Agrícola }\end{array}$ & $\begin{array}{l}\text { Mobilização do solo, fertilização e nutrição, vegetal, sementeiras e } \\
\text { plantações, proteção das culturas, regam e drenagem, colheita e pós- colheita, } \\
\text { integração das técnicas e produção agrícola. }\end{array}$ \\
\hline $\begin{array}{l}\text { Prática das principais } \\
\text { produções agrícolas }\end{array}$ & $\begin{array}{l}\text { Culturas arvenses, cereais de invernos, cereais de primavera verão, forragens } \\
\text { e pastagens, culturas orelícolas, fruteiras e vinhos, produção pecuária, } \\
\text { produção e política agrícola comum. }\end{array}$ \\
\hline \multicolumn{2}{|c|}{ Fonte: Elaborado pelas autoras, com base em Pedras Altas (2013). }
\end{tabular}

As propostas não são alinhadas com o contexto escolar como já foi citado, assim, fica explícita a necessidade de repensar e propor novos princípios para o componente curricular. Nesse sentido, entende-se que fatores externos também impedem que aconteça a aplicabilidade dessas diretrizes, tais como boa atuação profissional, visto que o professor precisa conhecer a realidade do aluno, ter didática, ensinar a matéria, motivar os alunos, estimular o debate e saber intervir e entender quando o aluno está desmotivado.

O território camponês é espaço geográfico, de cultura, de produção agroecológica, de soberania alimentar, enfim de agricultura familiar. É da terra que são extraídos os alimentos necessários à sua subsistência e o povo camponês são os autores da soberania alimentar, oferecendo saúde para a existência humana. A educação está inserida nas políticas sociais de incentivo ao povo campo e sem dúvida a mais relevante, pois tem um grande alcance na formação do ser humano e no contexto campesino.

A escola é o espaço mais frequentado por crianças e adolescentes durante o ano letivo, é formadora de opinião, referência de cultura e de pertencimento, por isso a preocupação com o distanciamento do currículo de Técnicas Agrícolas com o aspecto da territorialidade, com os saberes e fazeres daquele território. A educação deve ser um instrumento fortalecedor da territorialidade camponesa.

\section{Desdobramentos metodológicos da pesquisa}


O referido projeto de intervenção trata de uma pesquisa-ação que teve como ponto de partida o meu trabalho, uma das autoras, como professora na disciplina de Técnicas Agrícolas na Escola Municipal de Ensino Fundamental Neuza Brizola, localizada no Assentamento Nossa Senhora da Glória, Município de Pedras Altas. Desta forma, busca-se entender a contribuição do componente curricular de Técnicas Agrícolas na formação de alunos trabalhadores do campo visto que tenho observado o desinteresse dos alunos do campo pelo o que é proposto em aula, inclusive na Disciplina de Técnicas Agrícolas, que deve tratar da parte diversificada do contexto escolar. Como uma das possibilidades que possam explicar este desinteresse que os alunos externam e expressam, elaboramos as seguintes hipóteses: primeiro a causa do problema se dá pelo distanciamento do currículo escolar com a realidade da escola que está no campo; segundo as práticas pedagógicas desmotivadoras e desvinculadas do contexto; terceiro pode ser o desinteresse dos alunos pelo conhecimento formal. Para Thiollent (2011) o tema da pesquisa é a designação do problema prático e da área de conhecimento a serem abordados. Nesse sentido, a colocação dos problemas é de ordem prática, na área da educação. Ao referir-se sobre hipótese Thiollent (2011, p. 65) afirma que:

A hipótese desempenha um importante papel na organização da pesquisa: a partir da sua formulação, o pesquisador identifica as informações necessárias, evita a dispersão, focaliza determinados segmentos do campo de observações, seleciona os dados etc.

Nesse sentido após os dados coletados e analisados poderei constatar se as hipóteses elencadas acima estavam corretas ou equivocadas para, a partir daí, dar continuidade ao projeto. A construção metodológica teve início com uma fase exploratória para um primeiro levantamento, ou seja, um diagnóstico. Para Thiollent (2011) a fase exploratória consiste em descobrir o campo de pesquisa, os interessados e suas expectativas, é nessa fase que se estabelece um primeiro levantamento da situação e dos problemas práticos. É o momento de detectar apoios e resistências, convergências e divergências.

Nesse sentido o diagnóstico foi feito através de uma produção de relato no Google Drive, cuja temática refere-se a entender na visão discente como se dá os processos de ensino e de aprendizagem da escola do campo, considerando a contribuição da disciplina de Técnicas Agrícolas para o aluno do campo. A partir dos dados coletados e com a participação em uma reunião pedagógica, proposta pela direção da escola, com os professores dos anos iniciais e finais do Ensino Fundamental para tratar sobre a aprendizagem dos alunos que estava causando preocupação para o grupo docente, foi aproveitado o espaço e a pertinência dos assuntos que estavam sendo tratados, para uma roda de conversa com os professores. $\mathrm{Na}$ oportunidade foi falado sobre o desinteresse que os alunos expressam e externam com relação 
ao que é ensinado durante as aulas e o que se pretendia com o diagnóstico realizado com os alunos do nono ano. Ainda foi explicado que a escolha da turma do nono ano para fazer o diagnóstico consistiu em serem alunos da escola desde o pré-escolar e demonstrarem interesse em participar da produção de relato para o diagnóstico.

Para o objetivo geral ser atingido, os encontros da pesquisa-ação serão norteados pelos objetivos específicos que são: analisar o currículo da Disciplina de Técnicas Agrícolas, discutir juntamente com os alunos da turma do $9^{\circ}$ ano qual a perspectiva de produção agrícola que fundamenta a disciplina de Técnicas Agrícolas e formular princípios orientadores para uma proposta curricular direcionada ao aluno do campo. Para orientar as ações usaremos a Proposta Curricular da disciplina de Técnicas Agrícolas da Escola Neuza Brizola. Para avaliação das ações serão utilizados os seguintes instrumentos: diário de campo e análise documental das sínteses produzidas pelos alunos nos encontros realizados.

\section{Conclusão}

Embora a pesquisa seja realizada em uma escola do campo, é possível observar que a instituição apenas ocupa o espaço no campo, mas a proposta curricular não está centrada na formação do aluno do campo, o que implica distanciamento com a cultura escolar, e, de certo modo, distanciamento do aluno com o seu contexto campesino. Assim, levando em consideração o princípio filosófico da realidade como norte para a construção do conhecimento, a escola do campo se mostra distante de realizá-lo. Nesse sentido, perde-se saberes e fazeres do povo campesino que podem e devem contribuir quando pensada e organizada a proposta curricular de uma escola, fruto da luta de classes de um povo organizado, que sabe o que quer e para onde ir.

A cultura do povo campesino, é reconhecida pelos documentos nacionais e da escola, entretanto, não é considerada enquanto proposta pedagógica, negando a influencia da territorialidade na educação. Portanto, reafirma-se aqui a necessidade de a escola ocupar o papel de instrumento fortalecedor da cultura camponesa, permitindo não só a aquisição do conhecimento historicamente acumulado, mas também socialmente situado, produtor de sentidos e condutor de práticas que valorizem o território onde os alunos se situam.

\section{Referências}

ARROYO, Miguel. A educação básica e o movimento social do campo. In: ARROYO, Miguel Gonzalez; FERNANDES, Bernardo Mançano (Orgs.). A educação básica e o movimento social do campo. Brasília: Articulação por uma Educação Básica do Campo, 1999. p. 13-52. 
BRASIL. Resolução CNE/CEB 1, de 3 de abril de 2002. Institui Diretrizes Operacionais para a Educação Básica nas Escolas do Campo. Diário Oficial da União, Poder Executivo, Brasília, DF, 9 abr. 2002. Disponível em:

http://pronacampo.mec.gov.br/images/pdf/mn_resolucao_\%201_de_3_de_abril_de_2002.pdf. Acesso em: 29 dez. 2019.

Resolução n ${ }^{\circ}$ 2, de 28 de abril de 2008. Estabelece diretrizes complementares, normas e princípios para o desenvolvimento de políticas públicas de atendimento da Educação Básica do Campo. Diário Oficial da União, Poder Executivo, Brasília, DF, 29 abr. 2008. Disponível em:

http://portal.mec.gov.br/index.php?option=com_docman\&view=download\&alias $=11841$ rceb002-08-pdf\&category_slug=outubro-2012-pdf\&Itemid=30192. Acesso em: 29 dez. 2019.

CALDART, Roseli Salete. Por uma educação do Campo: traços de uma identidade em construção. In: ARROYO Miguel; CALDART, Roseli; MOLINA, Mônica (Orgs.). Por uma educação do campo. Petrópolis: Vozes, 2004. p. 147-158.

MOVIMENTO DOS TRABALHADORES RURAIS SEM TERRA. Princípios da educação no MST. São Paulo, 1996.

PEDRAS ALTAS. Proposta curricular da Escola Neuza Brizola do ano de 2013. Pedras Altas, 2013.

SOUZA, Maria Antônia de; MARCOCCIA, Patrícia Correia de Paula; Educação do campo, escolas, ruralidades e o projeto PNE. Revista da FAEEBA - Educação e Contemporaneidade, Salvador, v. 20, n. 36, p. 191-204, jul./dez. 2011. Disponível em:

https://www.revistas.uneb.br/index.php/faeeba/article/download/310/260. Acesso em: 29 dez. 2019.

THIOLLENT, Michel. Metodologia da pesquisa-ação. 18. ed. São Paulo: Cortez, 2011. 